Supporting Information

\title{
Vertical 1D/2D Heterojunction Architectures for Self-Powered Photodetection Application: GaN Nanorods Grown on Transition Metal Dichalcogenides
}

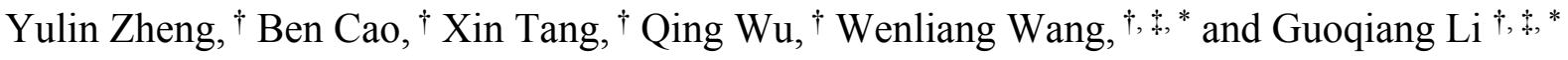

${ }^{\dagger}$ State Key Laboratory of Luminescent Materials and Devices, South China University of Technology, Guangzhou 510640, China.

Department of Electronic Materials, School of Materials Science and Engineering, South China University of Technology, Guangzhou 510640, China.

*Corresponding author, E-mail: wenliangwang@scut.edu.cn and msgli@scut.edu.cn 

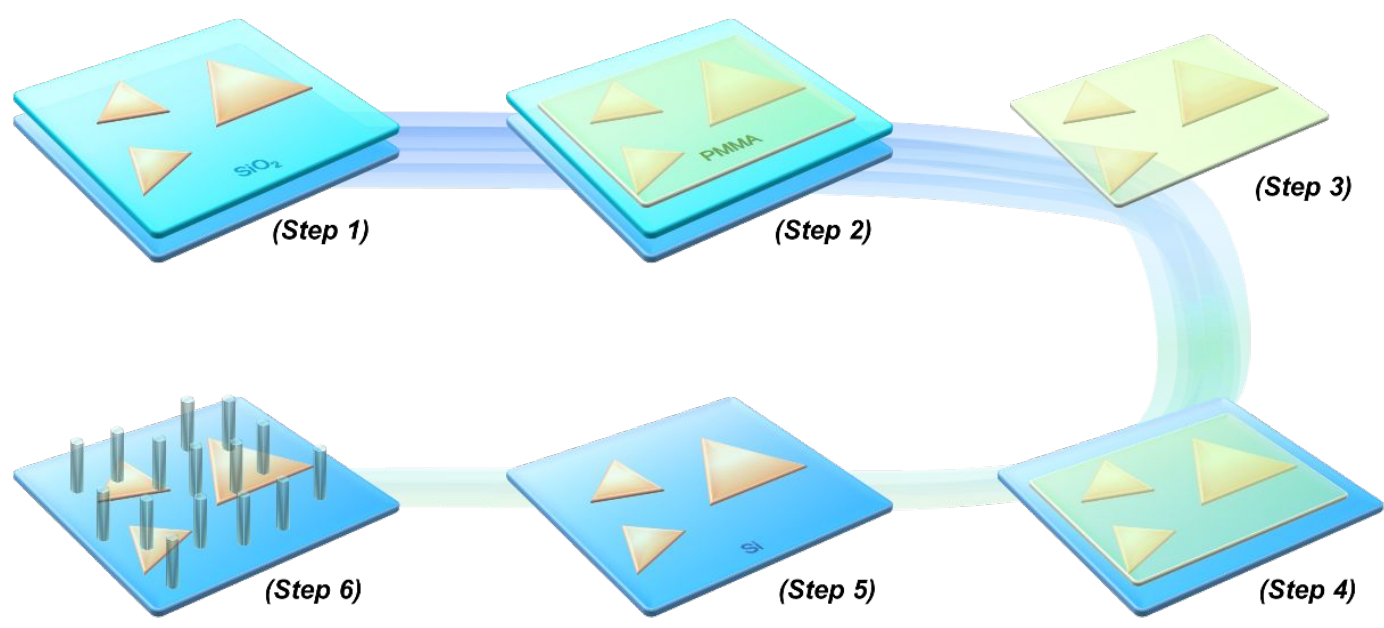

Figure S1. Schematic diagram for the fabrication process of vertical 1D/2D heterojunction: GaN nanorod arrays (NRAs) on TMDs/Si. Step 1: trilayer (3-L) TMDs grown on $\mathrm{SiO}_{2} / \mathrm{Si}$ substrate by chemical vapor deposition (CVD) method. Step 2: PMMA coating and cured as support. Step 3: etching of $\mathrm{SiO}_{2}$ substrate. Step 4: transfer of PMMA-coated 3-L TMDs film onto Si substrate. Step 5: removal of PMMA layer. Step 6: GaN NRAs grown on TMDs-on-Si substrate by plasma-assisted molecular beam epitaxy (PA-MBE) method. 

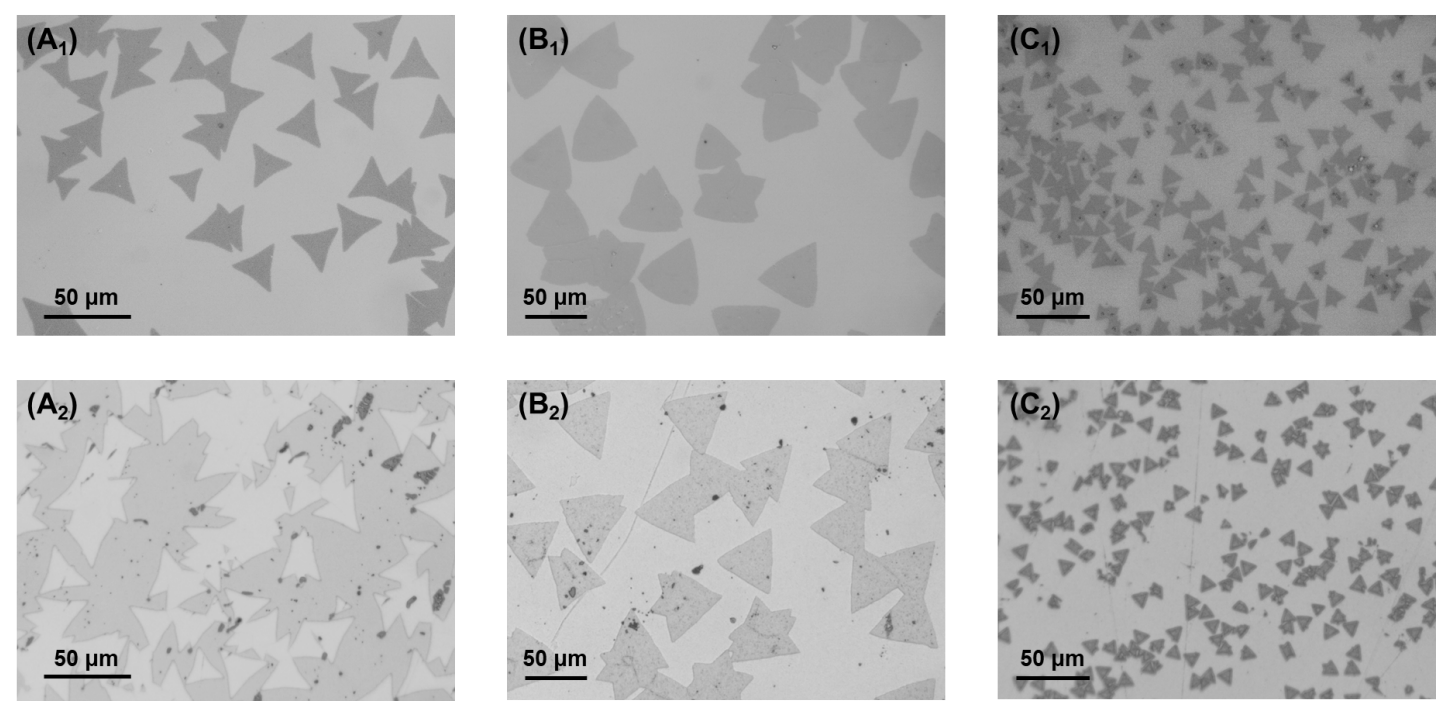

Figure S2. Optical microscopy images for: $\left.\left.\mathbf{A}_{\mathbf{1}}\right) \mathrm{MoS}_{2}, \mathbf{B}_{\mathbf{1}}\right) \mathrm{WS}_{2}$, and $\left.\mathbf{C}_{\mathbf{1}}\right) \mathrm{MoSe}_{2}$ grown on $\mathrm{SiO}_{2} / \mathrm{Si}$ substrate by $\mathrm{CVD}$ and for GaN NRAs grown on $\left.\left.\mathbf{A}_{2}\right) \mathrm{MoS}_{2} / \mathrm{Si}, \mathbf{B}_{2}\right) \mathrm{WS}_{2} / \mathrm{Si}$, and $\mathbf{C}_{2}$ ) $\mathrm{MoSe}_{2} / \mathrm{Si}$ substrates by PA-MBE. 

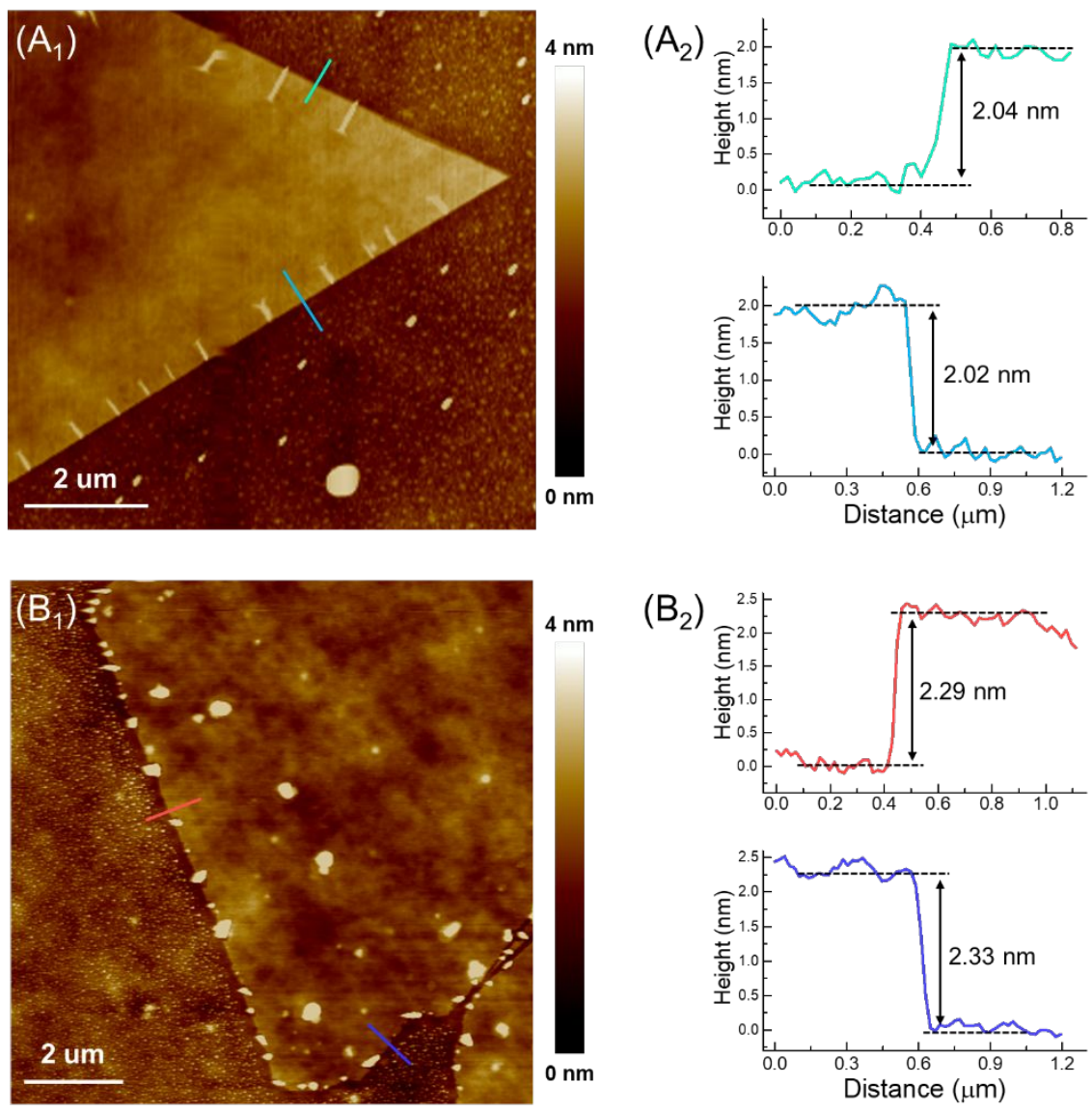

$\left(\mathrm{B}_{2}\right)$
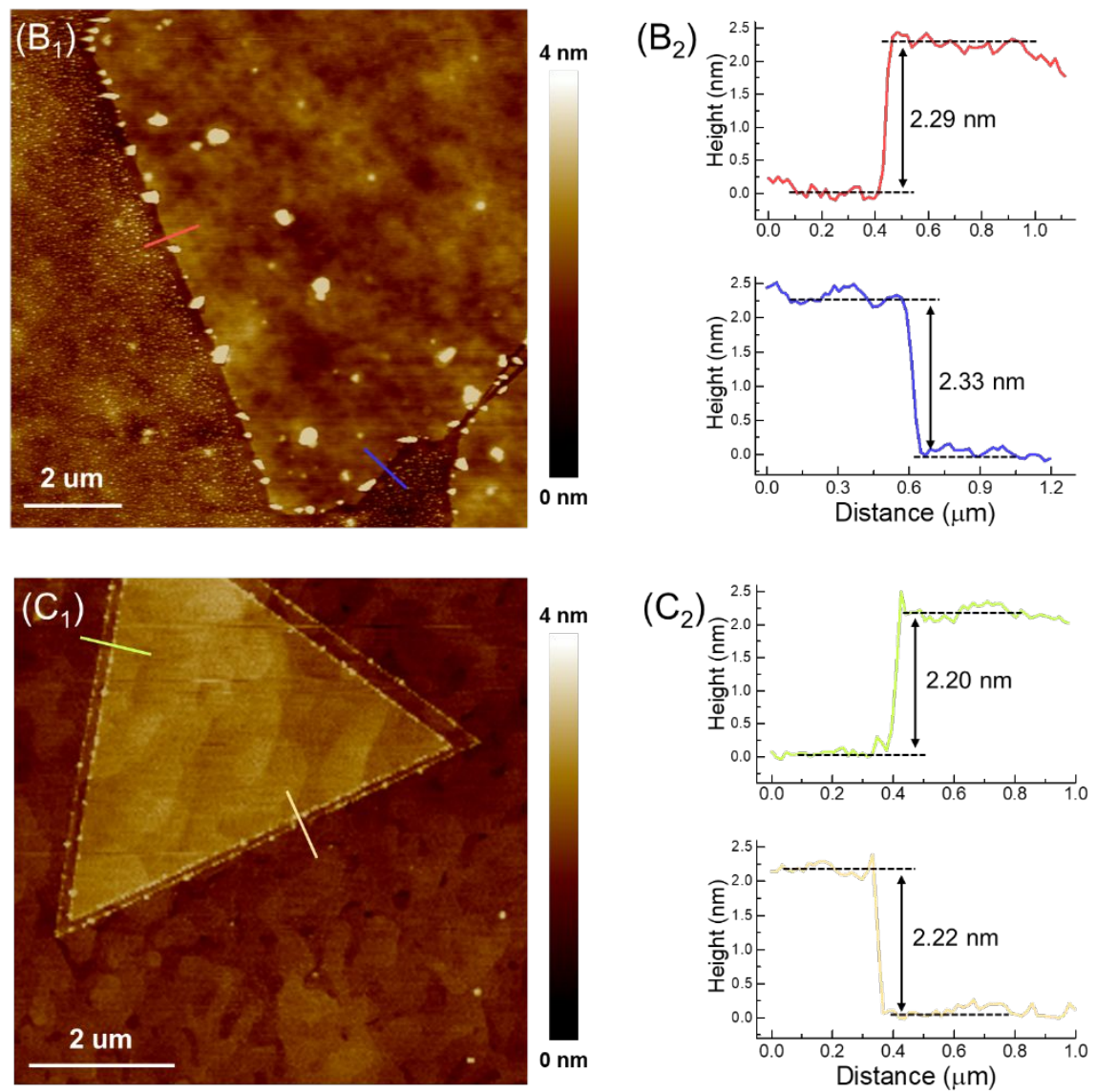

Figure S3. $\mathbf{A}_{\mathbf{1}}$ to $\mathbf{C}_{\mathbf{1}}$ ) Typical atomic force microscopy (AFM) images and the corresponding $\mathbf{A}_{2}$ to $\mathbf{C}_{2}$ ) line profiles of $\mathrm{MoS}_{2}, \mathrm{WS}_{2}$ and $\mathrm{MoSe}_{2}$ films grown on $\mathrm{SiO}_{2} / \mathrm{Si}$ substrate by $\mathrm{CVD}$, showing thickness of $\sim 2.02 \mathrm{~nm}, \sim 2.29 \mathrm{~nm}$ and $\sim 2.20 \mathrm{~nm}$, respectively. 


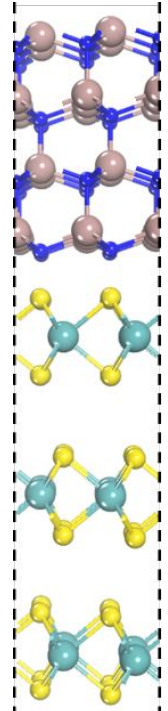

Layer 1

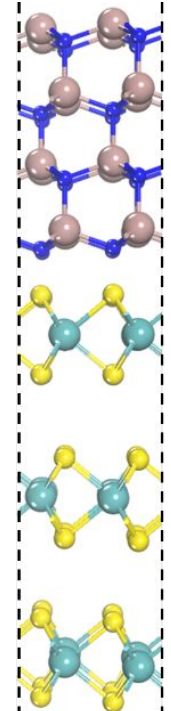

Layer 2

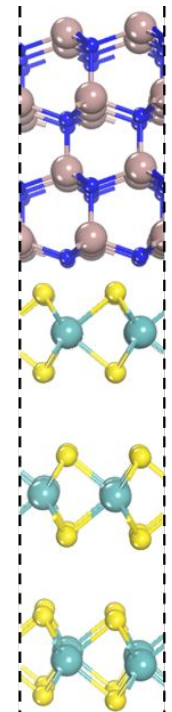

Layer 3

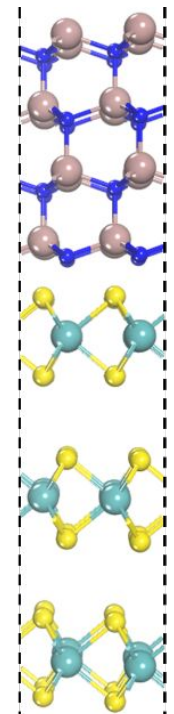

Layer 4

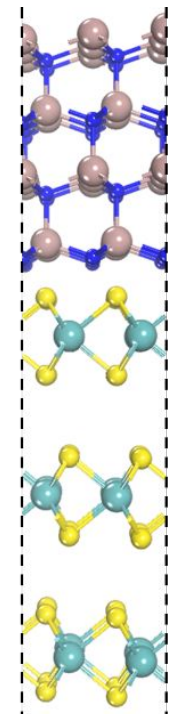

Layer 5

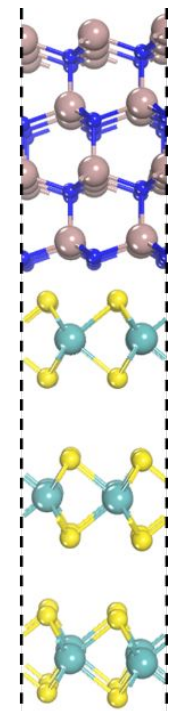

Layer 6

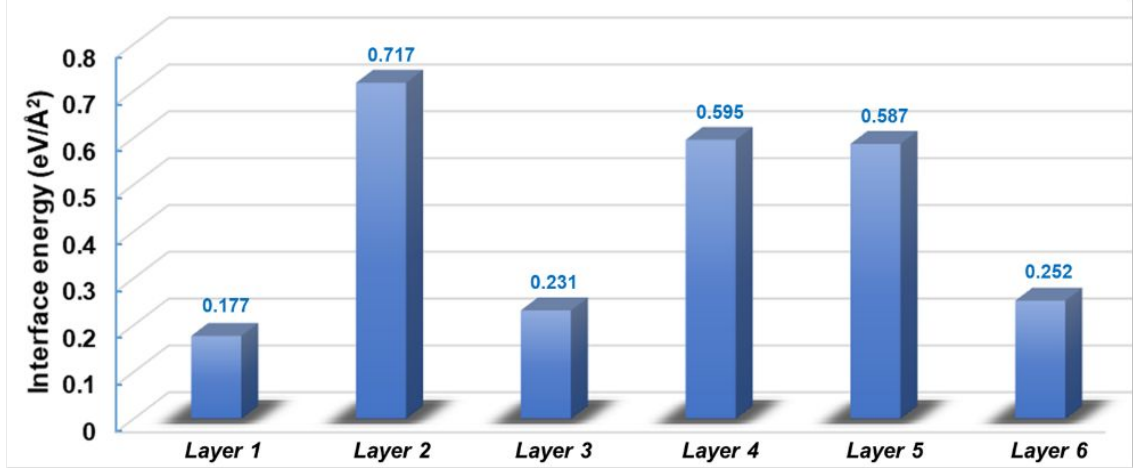

Figure S4. Interface energy (in $\mathrm{eV} / \AA^{2}$ ) for six interfacial layer models of $\mathrm{GaN}(0001) / \mathrm{MoS}_{2}(001)$ interfaces.

\section{Interface energy calculations.}

With the first-principles calculations, six interfacial layer models of $\mathrm{GaN}(0001) / \mathrm{MoS}_{2}(001)$ interfaces are constructed, named layer 1 to layer 6, shown in Figure S4. These interfacial layer models consist of $3-\mathrm{L} \mathrm{MoS}_{2}(001)$ connected to 8 atomic layers $\mathrm{GaN}(0001)$ and a $30 \AA$ area of vacuum layer to minimize the coupling perpendicular to the interface. The interface energy is defined as the needed energy to separate one interface into two free surfaces, which can be used to quantitatively predict the property and stabilization of the interface. ${ }^{1}$ The interface 
energy $E_{\text {interface }}$ can be calculated by the following Equation: ${ }^{2}$

$$
E_{\text {interface }}=\left(E_{\text {GaN }}^{\text {total }}+E_{\mathrm{MoS}_{2}}^{\text {total }}-E_{\text {total }}^{\text {tomoS }} / \mathrm{Mo}_{2}\right) / A
$$

where $E_{\mathrm{MoS}_{2}}^{\text {total }}, E_{G a N}^{\text {total }}$ and $E_{G a t}^{\text {total }} / \mathrm{MoS}_{2}$ are the total energies of the $\operatorname{MoS}_{2}(001), \mathrm{GaN}(0001)$ and interfacial layer model in the same supercell, respectively. $A$ is the vdW interface area. Generally, a stable interfacial layer model has a positive and large value of $E_{\text {interface. }}{ }^{2}$ The calculated interface energies are summarized in Figure S4. The results exhibit that the structure of layer 2 has the highest interface energy among all models, indicating that it has the strongest interfacial binding force. Moreover, the alignment epitaxial relationship for $\mathrm{GaN} / \mathrm{MoS}_{2}$ can be determined as $\mathrm{GaN}(0001) / / \mathrm{MoS}_{2}(001)$ and $\mathrm{GaN}\left(1_{1} \overline{1} 00\right) / / \mathrm{MoS}_{2}\left(1_{1} \overline{0}\right)$. 

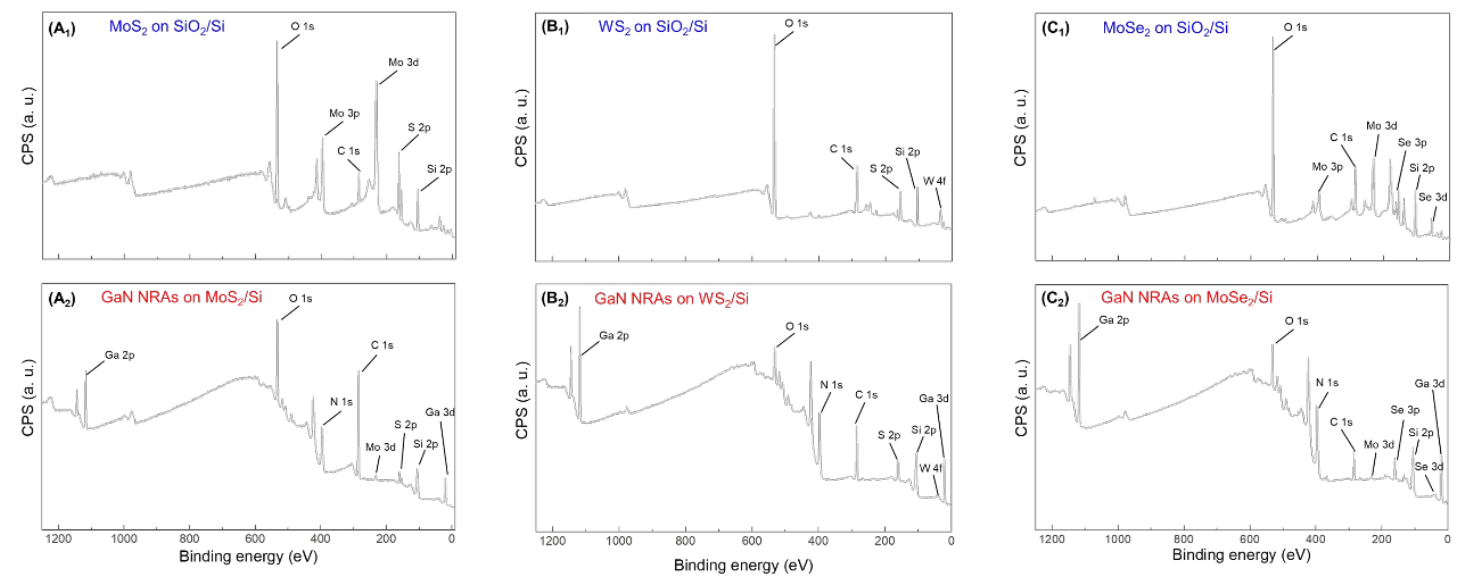

Figure S5. The survey X-ray photoelectron spectroscopy (XPS) spectra of the $\mathbf{A}_{1}$ ) $\mathrm{MoS}_{2}, \mathbf{B}_{\mathbf{1}}$ ) $\mathrm{WS}_{2}$, and $\left.\mathbf{C}_{\mathbf{1}}\right) \mathrm{MoSe}_{2}$ grown on $\mathrm{SiO}_{2} / \mathrm{Si}$ substrates and of GaN NRAs grown on $\left.\mathbf{A}_{\mathbf{2}}\right) \mathrm{MoS}_{2} / \mathrm{Si}$, $\left.\mathbf{B}_{2}\right) \mathrm{WS}_{2} / \mathrm{Si}$, and $\left.\mathbf{C}_{2}\right) \mathrm{MoSe}_{2} / \mathrm{Si}$ substrates. 
Table S1. Morphological parameters of GaN NRAs on $\mathrm{MoS}_{2} / \mathrm{Si}$ and on Si.

\begin{tabular}{ccc}
\hline Parameters & GaN NRAs on $\mathrm{MoS}_{2} / \mathrm{Si}$ & GaN NRAs on Si \\
\hline Average diameter (nm) & $66 \pm 6$ & $78 \pm 8$ \\
Average high (nm) & $330 \pm 10$ & $310 \pm 14$ \\
Average density $\left(\mathbf{c m}^{-2}\right)$ & $1.2 \times 10^{10}$ & $1.4 \times 10^{10}$ \\
\hline
\end{tabular}



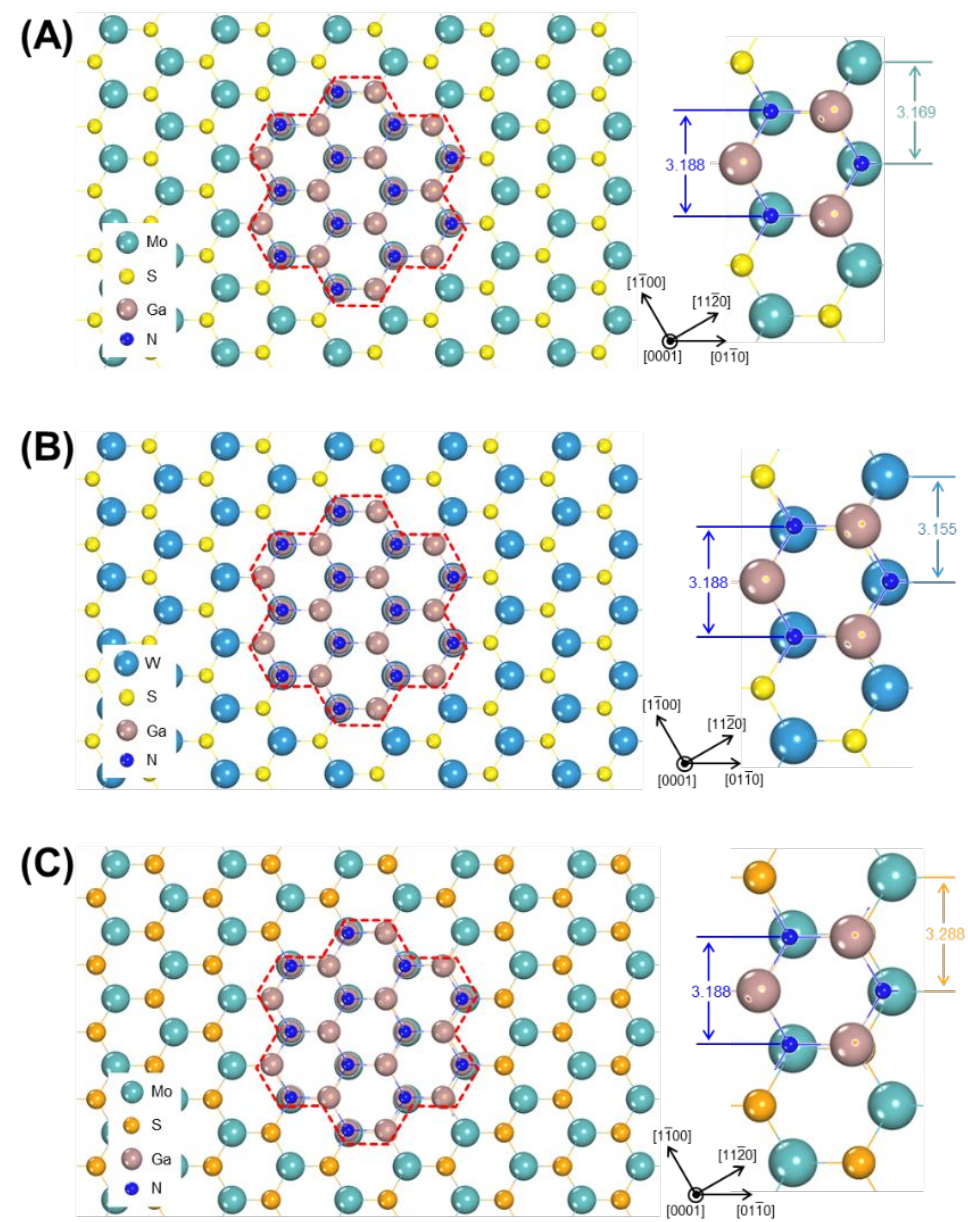

Figure S6. Schematic diagram of the atomic configuration to reveal the heteroepitaxial relationship of $\mathrm{GaN}(0001)\left[\overline{1}_{1} 00\right] \| \mathrm{TMDs}(001)\left[1_{1} 0\right]$ : A) $\left.\left.\mathrm{MoS}_{2} ; \mathbf{B}\right) \mathrm{WS}_{2} ; \mathbf{C}\right) \mathrm{MoSe}_{2}$. According to calculations, the lattice mismatch relationship between $\mathrm{GaN} / \mathrm{Si}$ of $-17 \%,{ }^{3} \mathrm{GaN} / \mathrm{MoS}_{2}$ of $0.6 \%,{ }^{4} \mathrm{GaN} / \mathrm{WS}_{2}$ of $1.0 \%,{ }^{5}$ and $\mathrm{GaN} / \mathrm{MoSe}_{2}$ of $-3.0 \%{ }^{4}$ are revealed. 


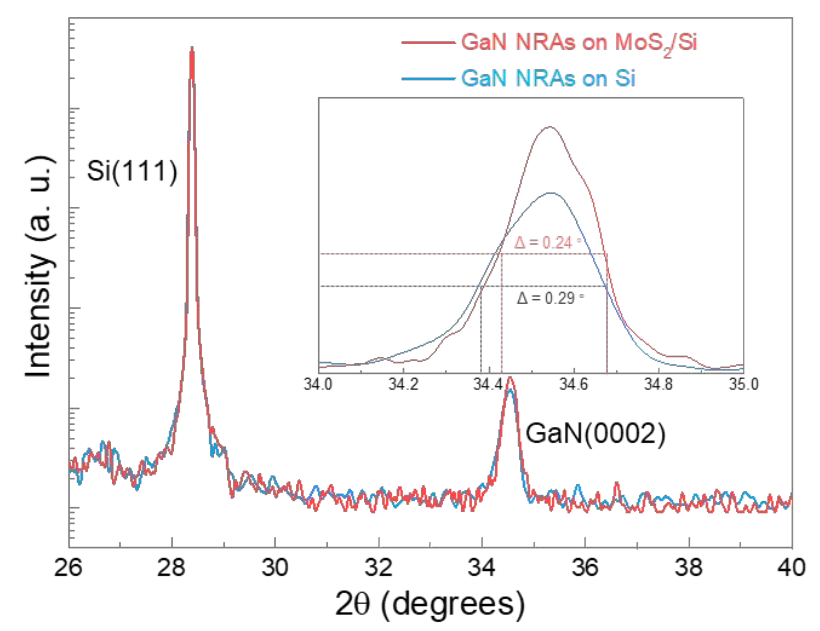

Figure S7. X-ray diffraction (XRD) $2 \theta^{-} \omega$ scan curves of GaN NRAs on $\mathrm{MoS}_{2}$ and on Si. Inset is the comparison of the full width at half-maximum (FWHM). The higher peak intensity and the smaller FWHM of the curve, indicating the higher crystalline quality of GaN NRAs. ${ }^{6}$ 


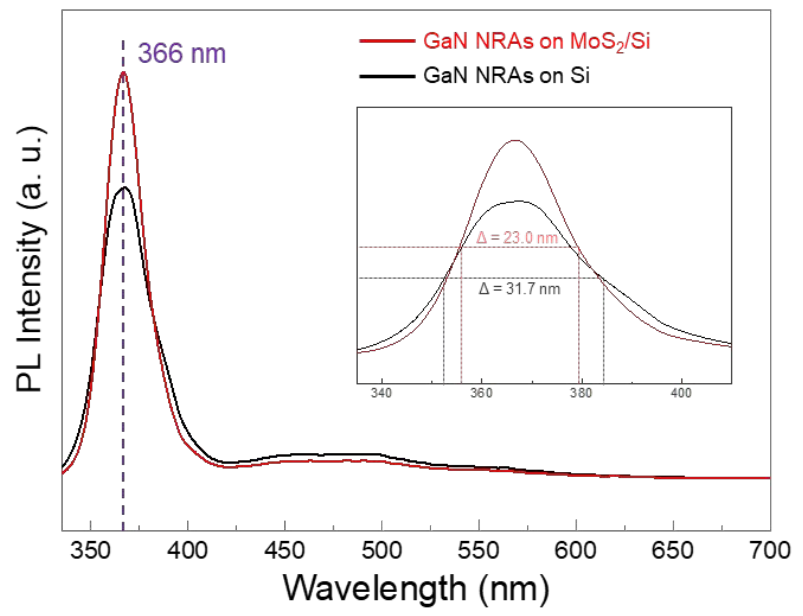

Figure S8. Room-temperature photoluminescence (PL) spectrum of GaN NRAs on $\mathrm{MoS}_{2}$ and on Si. Inset is the comparison of the FWHM. The higher peak intensity and the smaller FWHM of the curve, demonstrating the higher crystalline quality of GaN NRAs. ${ }^{2}$ 


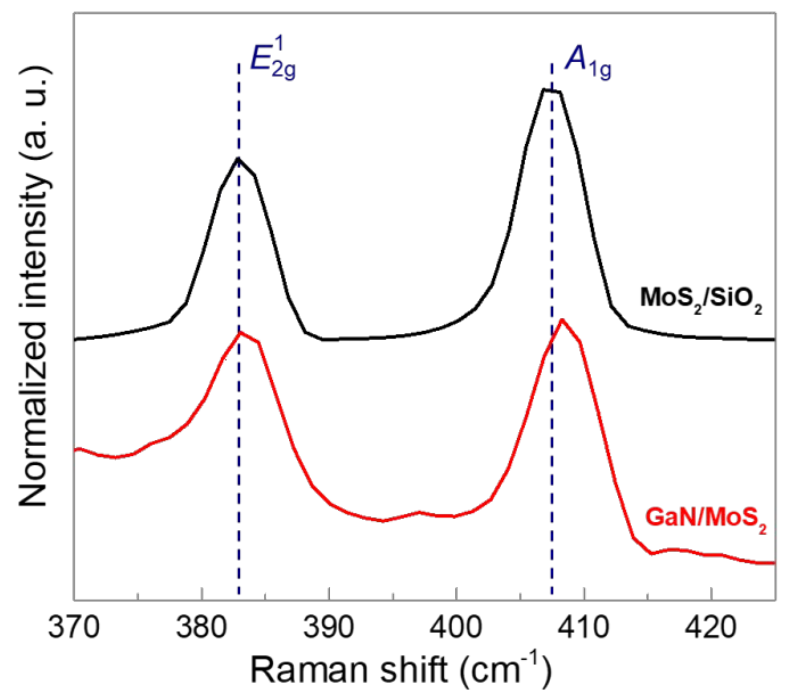

Figure S9. Raman spectra for $\mathrm{MoS}_{2} / \mathrm{SiO}_{2}$ and $\mathrm{GaN} / \mathrm{MoS}_{2}$, where the ordinate intensity was normalized for comparison. A blue-shift of the $\mathrm{A}_{1 \mathrm{~g}}$ modes of $\mathrm{GaN} / \mathrm{MoS}_{2}$ can be observed. 

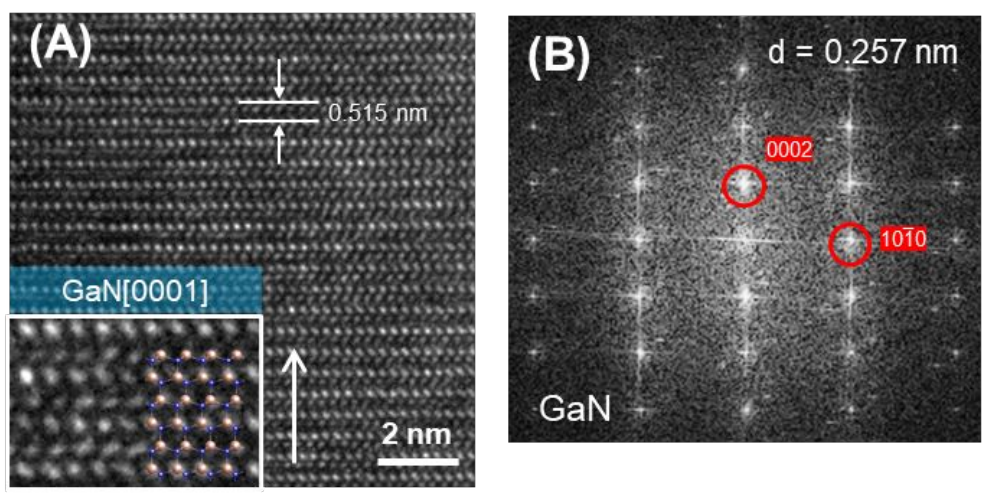

Figure S10. High-resolution TEM atomic images for GaN nanorod grown on $\mathrm{MoS}_{2}$ and the corresponding selected-area diffraction (SAD) pattern obtained through fast Fourier transform (FFT) process of TEM image. 

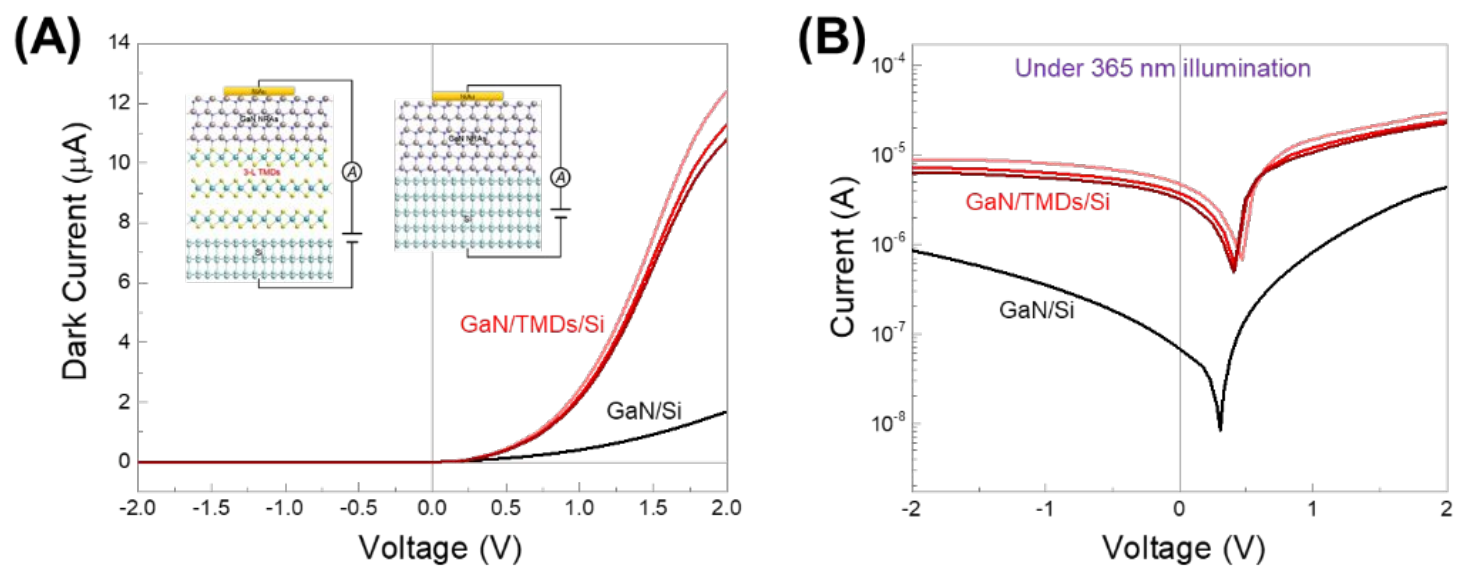

Figure S11. A) Typical current-voltage $(I-V)$ characteristics (in linear ordinate scale) of GaN/TMDs/Si (red curves, color changed from light to deep by: $\mathrm{MoS}_{2}, \mathrm{WS}_{2}$ and $\mathrm{MoSe}_{2}$ ) and $\mathrm{GaN} / \mathrm{Si}$ heterojunctions photodetectors in the dark (black curve), showing an asymmetrical rectification characteristic under forward and reverse bias. Insets are the schematically structure of the GaN/TMDs vdW heterojunction photodetector device. B) $I-V$ characteristics (in logarithmic ordinate scale) of GaN/TMDs/Si and GaN/Si heterojunctions photodetectors under $365 \mathrm{~nm}$ illumination with a power density of $10 \mathrm{~mW} \mathrm{~cm} \mathrm{~cm}^{-2}$. 

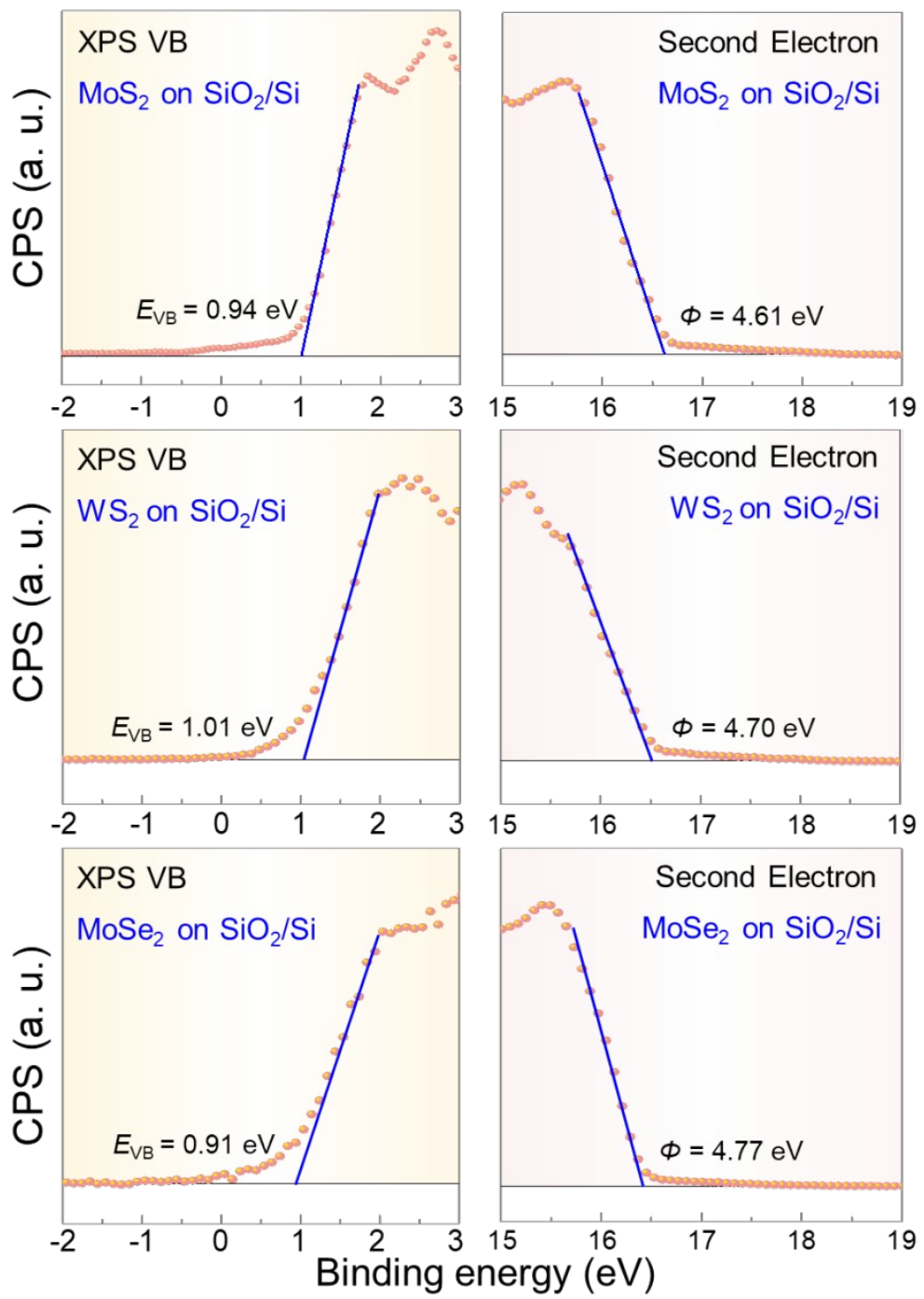

Figure S12. XPS valence band (VB) edge and ultraviolet photoelectron spectra (UPS) work function spectra for TMDs: $\mathrm{MoS}_{2} ; \mathrm{WS}_{2} ; \mathrm{MoSe}_{2}$. The difference between VB maximum and Fermi energy $\left(E_{\mathrm{VB}}\right)$ are estimated to be $0.94,1.01$ and $0.91 \mathrm{eV}$, respectively. The work functions $(\Phi)$ are determined to be $4.61,4.70$ and $4.77 \mathrm{eV}$, respectively. 
(A)

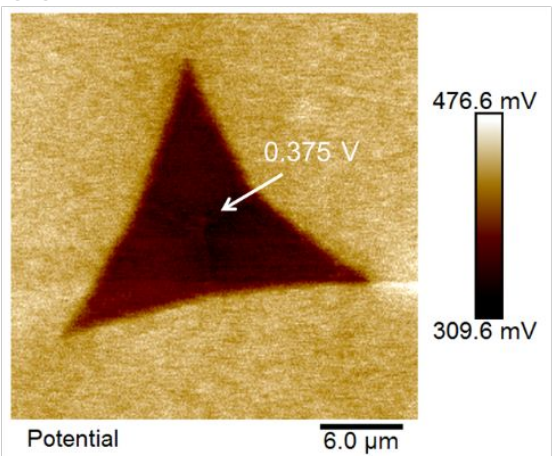

(B)

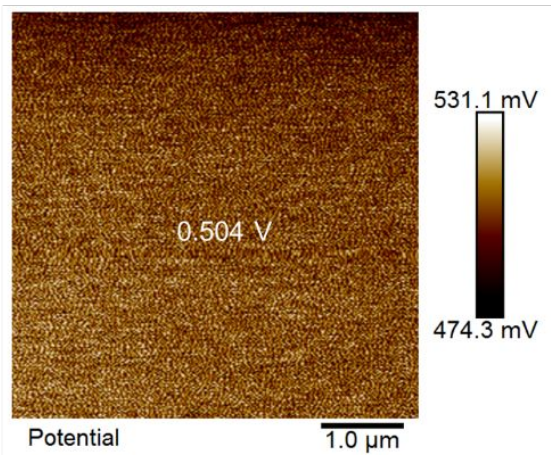

Figure S13. Kelvin probe force microscopy (KPFM) images for A) $\mathrm{MoS}_{2}$ flake and B) p-Si substrate, where the average surface contact potential differences (CPD) are determined as $0.375 \mathrm{~V}$ and $0.504 \mathrm{~V}$, respectively. According to the potential of the probe (5.101 V) calibrated by standard Au sample, ${ }^{7}$ the work function of $\mathrm{MoS}_{2}$ flake and p-Si substrate are calculated as $4.736 \mathrm{eV}$ and $4.597 \mathrm{eV}$, respectively. 

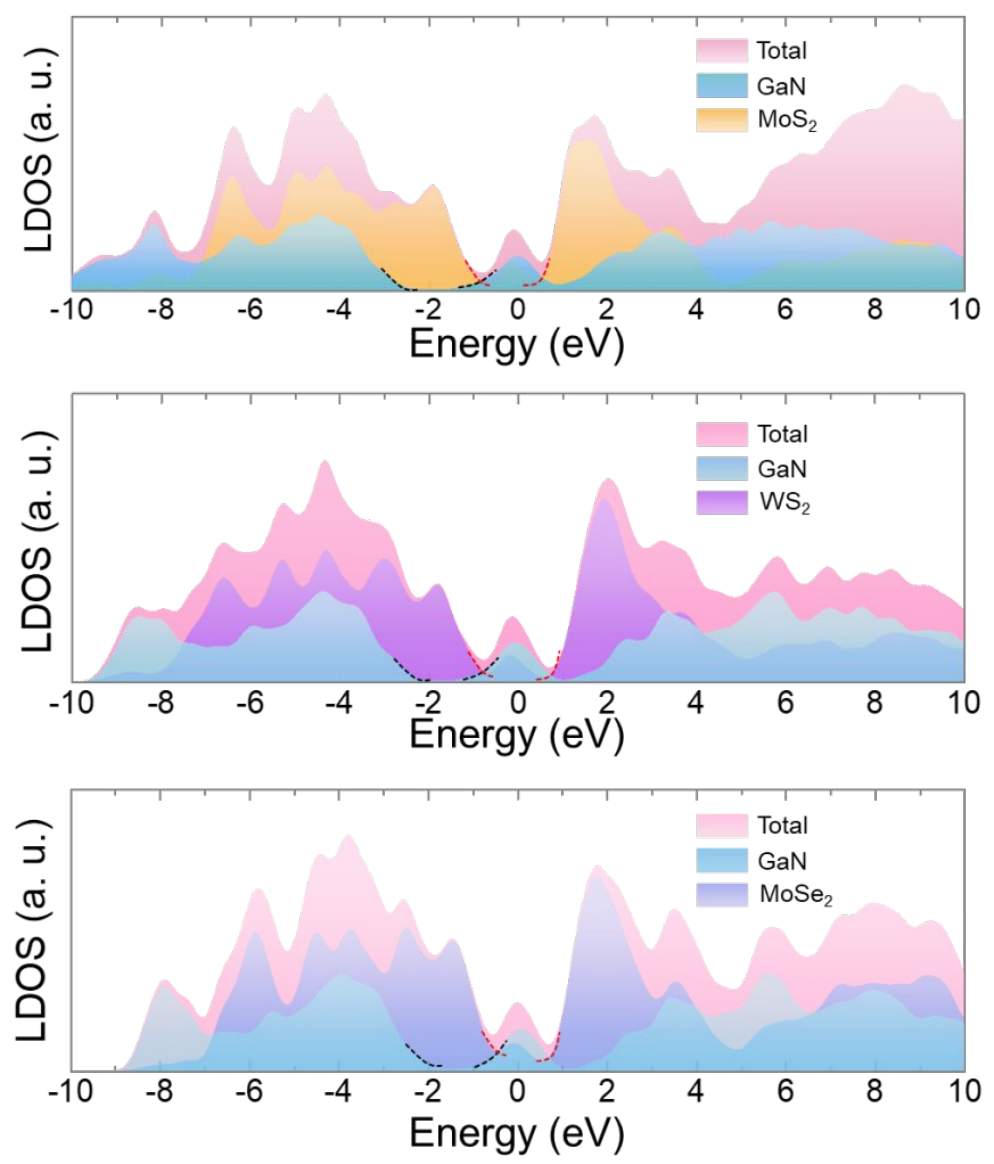

Figure S14. Calculated local density of states (LDOS) of GaN/TMDs hybrid (TMDs=MoS ${ }_{2}$, $\mathrm{WS}_{2}$, and $\mathrm{MoSe}_{2}$ ), which shows that TMDs have a higher conduction band minimum and a higher valence band maximum than GaN, revealing the type-II band alignment for GaN/TMDs vdW heterojunction. ${ }^{8}$ 

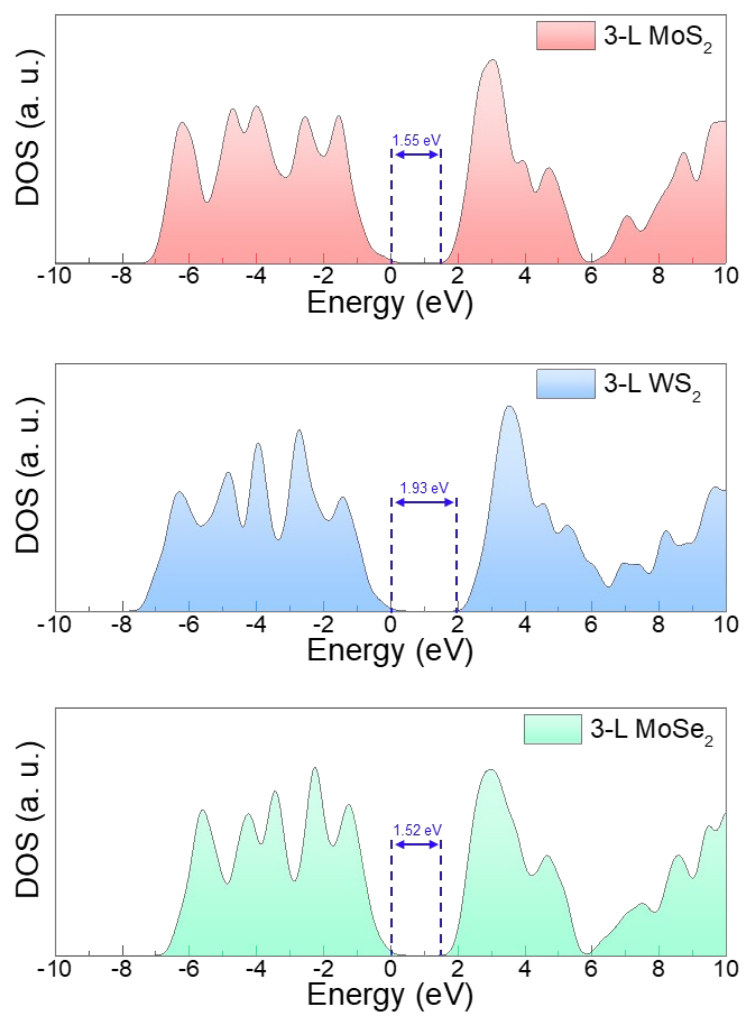

Figure S15. Calculated DOS of 3-L TMDs: $\mathrm{MoS}_{2}, \mathrm{WS}_{2}$, and $\mathrm{MoSe}_{2}$, revealing the band gap of $1.55,1.93$, and $1.52 \mathrm{eV}$, respectively. 

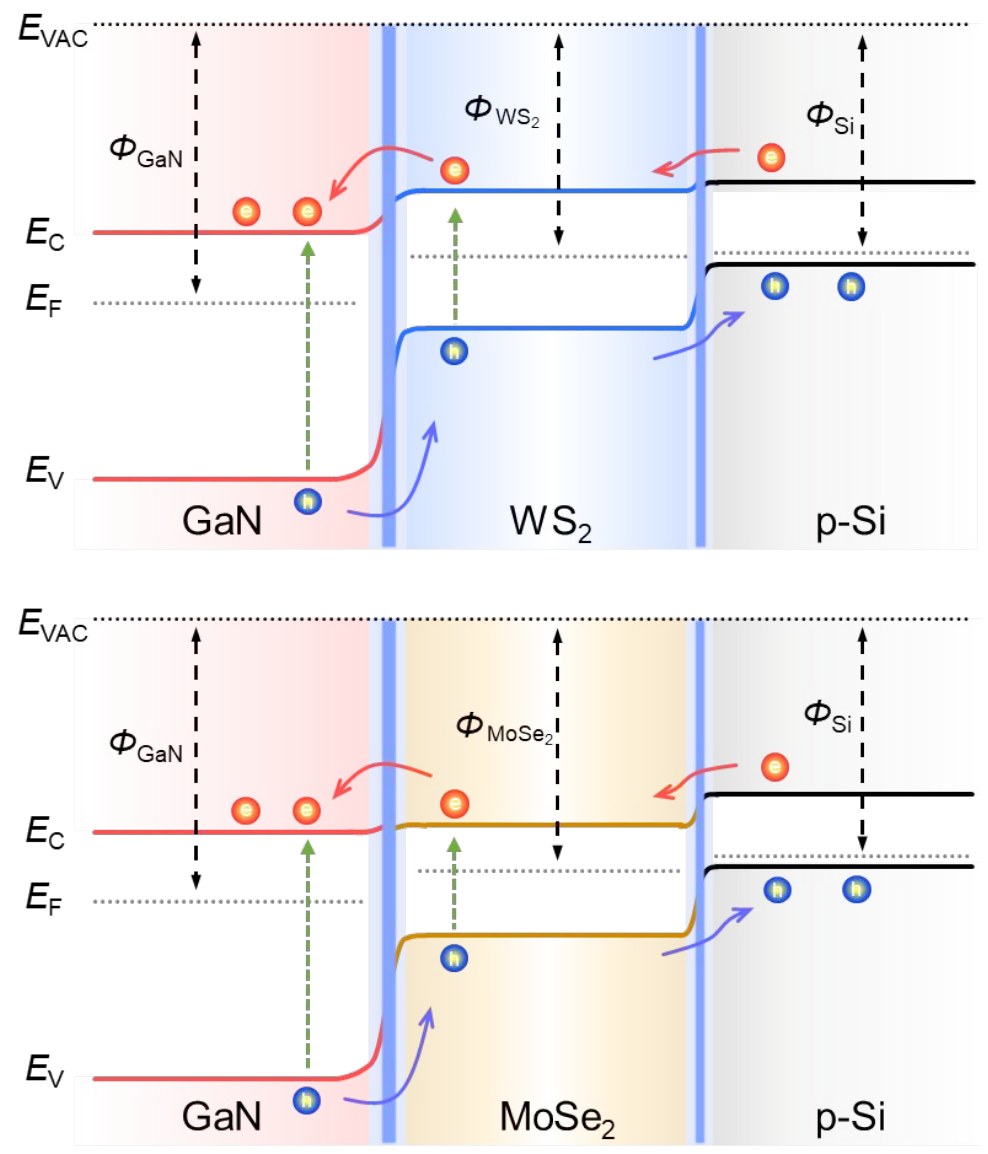

Figure S16. Proposed type-II band alignment diagrams of $\mathrm{GaN} / \mathrm{WS}_{2} / \mathrm{Si}$ and $\mathrm{GaN} / \mathrm{MoSe} \mathrm{S}_{2} / \mathrm{Si}$ vertical vdW heterojunction. 
Table S2. The comparison of the performance of photodetectors between our $\mathrm{GaN}$ NRAs/TMDs heterostructure and other reported 2D vdW heterostructures.

\begin{tabular}{ccccc}
\hline Description & $\begin{array}{c}\text { Bias } \\
(\mathbf{V})\end{array}$ & $\begin{array}{c}\text { Responsivity } \\
\left(\mathbf{A} \cdot \mathbf{W}^{-1}\right)\end{array}$ & $\begin{array}{c}\text { Rise/fall time } \\
(\mathbf{m s})\end{array}$ & Ref. \\
\hline $\mathrm{GaN} \mathrm{NRA} / \mathrm{MoS}_{2}$ & 0 & $10.1 @ 365 \mathrm{~nm}$ & $<0.5 / 4.2$ & $\begin{array}{c}\text { This } \\
\text { work }\end{array}$ \\
$\mathrm{MXene} / \mathrm{GaN}$ & 0 & $0.284 @ 355 \mathrm{~nm}$ & $0.007 / 1.67$ & 9 \\
$\mathrm{WSe}_{2} / \mathrm{Bi}_{2} \mathrm{O}_{2} \mathrm{Se}$ & 0 & $0.284 @ 532 \mathrm{~nm}$ & $0.02 / 0.02$ & 10 \\
$\mathrm{MoTe}_{2} / \mathrm{MoS}_{2}$ & 0 & $0.046 @ 254 \mathrm{~nm}$ & $0.06 / 0.025$ & 11 \\
$\mathrm{PtSe}_{2} / \mathrm{GaN}$ & 0 & $0.193 @ 265 \mathrm{~nm}$ & $0.045 / 0.102$ & 12 \\
$\mathrm{GaSe}_{\mathrm{MoS}}$ & 0 & $0.9 @ 450 \mathrm{~nm}$ & $5.0 / 5.0$ & 13 \\
$\mathrm{GaTe}_{2} \mathrm{MoS}_{2}$ & 0 & $1.365 @ 633 \mathrm{~nm}$ & $<10 /<10$ & 14 \\
$\mathrm{MoS}_{2} / \mathrm{WS}_{2}$ & 0 & $0.00436 @ 532 \mathrm{~nm}$ & $4 / 4$ & 15 \\
$\mathrm{MoS}_{2} / \mathrm{GaN}$ & 0 & $0.187 @ 265 \mathrm{~nm}$ & $0.3 / 3.6$ & 16 \\
\hline
\end{tabular}




\section{References}

(1) Han, Y. F.; Dai, Y. B.; Wang, J.; Shu, D.; Sun, B. D. First-Principles Calculations on Al/AlB 2 Interfaces. Appl. Surf. Sci. 2011, 257, 7831-7836.

(2) Wang, W.; Zheng, Y.; Li, X.; Li, Y.; Huang, L.; Li, G. High-performance nonpolar a-plane GaN-based metal-semiconductor-metal UV photo-detectors fabricated on $\mathrm{LaAlO}_{3}$ substrates. J. Mater. Chem. C 2018, 6, 3417-3426.

(3) Zhu, D.; Wallis, D. J.; Humphreys, C. J. Prospects of III-Nitride Optoelectronics Grown on Si. Rep. Prog. Phys. 2013, 76, 106501.

(4) Gupta, P.; Rahman, A. A.; Subramanian, S.; Gupta, S.; Thamizhavel, A.; Orlova, T.; Rouvimov, S.; Vishwanath, S.; Protasenko, V.; Laskar, M. R.; Xing, H. G.; Jena, D.; Bhattacharya, A. Layered Transition Metal Dichalcogenides: Promising Near-Lattice-Matched Substrates for GaN Growth. Sci. Rep. 2016, 6, 23708.

(5) Yun, W. S.; Han, S. W.; Hong, S. C.; Kim, I. G.; Lee, J. D. Thickness and Strain Effects on Electronic Structures of Transition Metal Dichalcogenides: $2 \mathrm{H}-\mathrm{MX}_{2}$ Semiconductors $(\mathrm{M}=$ Mo, W; $\mathrm{X}=\mathrm{S}, \mathrm{Se}, \mathrm{Te})$. Phys. Rev. B 2012, 85, 033305.

(6) Xiong, J.; Tang, J.; Liang, T.; Wang, Y.; Xue, C.; Shi, W.; Zhang, W. Characterization of Crystal Lattice Constant and Dislocation Density of Crack-Free GaN Films Grown on Si(111). Appl. Surf. Sci. 2010, 257, 1161-1165.

(7) Ruzmetov, D.; Zhang, K.; Stan, G.; Kalanyan, B.; Bhimanapati, G. R.; Eichfeld, S. M.; Burke, R. A.; Shah, P. B.; O’Regan, T. P.; Crowne, F. J.; Birdwell, A. G.; Robinson, J. A.; Davydov, A. V.; Ivanov, T. G. Vertical 2D/3D Semiconductor Heterostructures Based on Epitaxial Molybdenum Disulfide and Gallium Nitride. ACS Nano 2016, 10, 3580-3588.

(8) Lin, J.; Zhang, Z.; Chai, J.; Cao, B.; Deng, X.; Wang, W.; Liu, X.; Li, G. Highly Efficient InGaN Nanorods Photoelectrode by Constructing Z-scheme Charge Transfer System for Unbiased Water Splitting. Small 2021, 17, 2006666.

(9) Song, W.; Chen, J.; Li, Z.; Fang, X. Self-Powered MXene/GaN van der Waals Heterojunction Ultraviolet Photodiodes with Superhigh Efficiency and Stable Current Outputs. Adv. Mater. 2021, 33, 2101059.

(10)Luo, P.; Wang, F.; Qu, J.; Liu, K.; Hu, X.; Liu, K.; Zhai, T. Self-Driven $\mathrm{WSe}_{2} / \mathrm{Bi}_{2} \mathrm{O}_{2} \mathrm{Se}$ Van der Waals Heterostructure Photodetectors with High Light On/Off Ratio and Fast Response. Adv. Funct. Mater. 2021, 31, 2008351.

(11)Chen, Y.; Wang, X.; Wu, G.; Wang, Z.; Fang, H.; Lin, T.; Sun, S.; Shen, H.; Hu, W.; Wang, J.; Sun, J.; Meng, X.; Chu, J. High-Performance Photovoltaic Detector Based on $\mathrm{MoTe}_{2} / \mathrm{MoS}_{2}$ Van der Waals Heterostructure. Small 2018, 14, 1703293.

(12)Zhuo, R.; Zeng, L.; Yuan, H.; Wu, D.; Wang, Y.; Shi, Z.; Xu, T.; Tian, Y.; Li, X.; Tsang, Y. H. In-Situ Fabrication of $\mathrm{PtSe}_{2} / \mathrm{GaN}$ Heterojunction for Self-Powered Deep Ultraviolet Photodetector with Ultrahigh Current On/Off Ratio and Detectivity. Nano Res. 2019, 12, 183 189.

(13)Zou, Z.; Liang, J.; Zhang, X.; Ma, C.; Xu, P.; Yang, X.; Zeng, Z.; Sun, X.; Zhu, C.; Liang, D.; Zhuang, X.; Li, D.; Pan, A. Liquid-Metal-Assisted Growth of Vertical GaSe/MoS 2 p-n Heterojunctions for Sensitive Self-Driven Photodetectors. ACS Nano 2021, 15, 10039-10047. (14)Yang, S.; Wang, C.; Ataca, C.; Li, Y.; Chen, H.; Cai, H.; Suslu, A.; Grossman, J. C.; Jiang, C.; Liu, Q.; Tongay, S. Self-Driven Photodetector and Ambipolar Transistor in Atomically 
Thin GaTe-MoS 2 p-n vdW Heterostructure. ACS Appl. Mater. Interfaces 2016, 8, 2533-2539. (15)Wu, W.; Zhang, Q.; Zhou, X.; Li, L.; Su, J.; Wang, F.; Zhai, T. Self-Powered Photovoltaic Photodetector Established on Lateral Monolayer $\mathrm{MoS}_{2}-\mathrm{WS}_{2}$ Heterostructures. Nano Energy 2018, 51, 45-53.

(16)Zhuo, R.; Wang, Y.; Wu, D.; Lou, Z.; Shi, Z.; Xu, T.; Xu, J.; Tian, Y.; Li, X. HighPerformance Self-Powered Deep Ultraviolet Photodetector Based on $\mathrm{MoS}_{2} / \mathrm{GaN} \mathrm{p}-\mathrm{n}$ Heterojunction. J. Mater. Chem. C 2018, 6, 299-303. 